\title{
Antioxidant ability of Chenopodium formosanum extracted using an ethanol- ammonium sulfate two-phase system
}

\author{
Wei-Hsun Wang ${ }^{1,2,3,4,5,6}$, Wei-Lin Li ${ }^{6}$, Cheng-You Chen ${ }^{7}$, Min-Yun Chang ${ }^{6}$, Shu-Ling Huang ${ }^{6}$, \\ Chia-Hung Shih ${ }^{6,8}$ and Yung-Sheng Lin $6,7,9^{*}$ (D)
}

\begin{abstract}
Background: Chenopodium formosanum (CF) provides the human body with numerous nutritional components. This study used the two-phase system to identify an efficient method to obtain CF extracts. CF extraction was performed using an ethanol-ammonium sulfate two-phase system. The efficacy of different CF extracts with five types of antioxidant ability was tested and compared with traditional aqueous and alcohol extractions.

Results: The results showed that a separated top of the two-phase system extract had higher total phenol content (120.35 $\pm 5.80 \mathrm{mg}$ gallic acid equivalent/g dry extract), total flavonoid content (447.06 $\pm 16.57 \mathrm{mg}$ quercetin equivalent/g dry extract) and reducing ability ( $284.48 \pm 4.60 \mathrm{mg}$ vitamin C equivalent/g dry extract) than those of other extracts. Furthermore, the separated top of the two-phase system extract and the top of the two-phase system extract had higher 1,1-diphenyl-2-picrylhydrazyl free radical scavenging ability and 2,2'-azino-bis(3-ethylbenzothiazoline-6-sulfonic acid) free radical scavenging ability than those of the water extract, alcohol extract, bottom of twophase system extract, and separated bottom of two-phase system extract.
\end{abstract}

Conclusions: The results indicate that CF has great potential for use in natural plant health supplements and skin care products and that the two-phase extraction system can yield an effective CF extract.

Keywords: Antioxidant, Extract, Chenopodium formosanum, Two-phase

\section{Graphical Abstract}

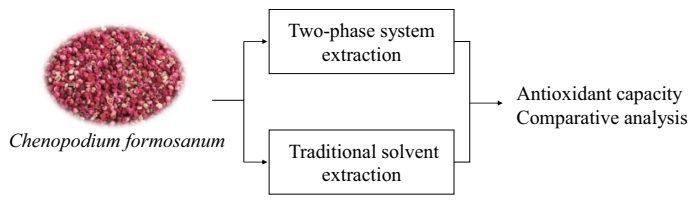

\section{Background}

Chenopodium formosanum (CF), a grain native to Taiwan, has long been regarded as an important plant by indigenous people; however, in the past it was often

\footnotetext{
*Correspondence: linys@nuu.edu.tw

${ }^{6}$ Department of Chemical Engineering, National United University, Miaoli 360001, Taiwan

Full list of author information is available at the end of the article
}

confused with quinoa [1]. CF is mainly distributed throughout southern and eastern Taiwan, and the plant can grow up to $2 \mathrm{~m}$ tall. Farmers usually plant CF in spring or autumn and can harvest it in 100 days.

CF has a bright color that comes from betalains [2]. Betalains include purple-red anthocyanins (betacyanins) and orange-yellow betaxanthins, which have a strong coloring ability and are believed to have positive physiological effects on humans [3]. Betanin has 
also proven to be an effective antioxidant component in $\mathrm{CF}$, with the strongest antioxidant capacity and stability with a $\mathrm{pH}$ of 5 [1]. CF also contains phenolic compounds and flavonoids, and a high-performance liquid chromatography chart showed that 8 phenolic compounds and 14 flavonoids were found in dehulled CF seeds [4]. CF has also proven tentatively effective in disease prevention. For example, feeding CF to rats with colon cancer lesions demonstrated some efficacy in preventing colon cancer progression [5]. CF extracts can also protect the skin from damage caused by ultraviolet rays [6]. Additionally, $\mathrm{CF}$ water extract can reduce hypertension [7], and the brightly colored grain is used as an insect repellent and as a decoration by indigenous people in Taiwan [1].

The aqueous two-phase system (ATPS) is a liquidliquid extraction technology that has recently attracted considerable attention. Studies have reported the successful use of this system for plant extraction, sewage treatment, separation of precious metals, and other applications $[8,9]$. In addition, because of its characteristics of stratification, environmental protection, extraction selectivity, and easy scale-up, the ATPS has been gradually applied to the separation and purification of small molecules [10].

ATPS has been successfully applied to the extraction of components from plants such as aloe leaf [11], blueberry [12], eucalyptus [13], garlic powder [14], grape seed [15], ginseng [16], honeysuckle [17], Lilium davidii var. unicolor Salisb [18], Lentinus edodes [19], ramie [20], Radix Sophorae Tonkinensis [21], Schisandra chinensis Baill [22] and wheat valley [23]. Compared with other liquid-liquid extractions, APTS is simpler and lower in cost due to the high recovery of phase-forming components [22]. The lignan purity of Schisandra chinensis Baill extracted using an optimized ATPS increased from $0.98 \%$ to $4.49 \%$ [22]. The purity of allicin extracted from garlic by using an ATPS (68.4\%) was much higher than that obtained using ethanol extract (31.8\%), and the bioactive tests on extracts by an ATPS displayed an effective antioxidant activity [24]. Comparing the extraction results from Tagetes erecta L. by using an ATPS and by using Soxhlet extraction, ATPS extraction manifested a superior total polyphenol content and antioxidant activity [25].

ATPS is a novel technology for plant extraction; however, no report has yet described ATPS extraction for CF. Compared with traditional extraction methods, ATPS has the advantages of low cost and easy scale-up. Consequently, this study used the ethanol-ammonium sulfate two-phase system for CF extraction and compared the results with those from traditional extraction.

\section{Materials and methods \\ Reagents}

Aluminum (III) chloride, 2,2'-azino-bis(3-ethylbenzothiazoline-6-sulfonic acid) (ABTS), and quercetin were obtained from Alfa Aesar (Tewksbury, MA, USA). Iron (III) chloride hexahydrate was provided by J. T. Baker (Phillipsburg, NJ, USA). Trichloroacetic acid, sodium carbonate, and sodium phosphate dibasic dehydrate were purchased from Riedel-de Haën (Seelze, Germany). Folin-Ciocalteu reagent was supplied by Fisher Scientific (Loughborough, Leicestershire, UK). Potassium ferricyanide was purchased from First Chemical Co. (Pascagoula, MS, USA). Gallic acid was obtained from Fluka (Neu-Ulm, Germany). Ammonium sulfate and potassium persulfate were procured from Showa Chemical Co. (Tokyo, Japan). Vitamin C was obtained from Acros (Geel, Belgium). 1,1-Diphenyl-2-picrylhydrazyl (DPPH) and sodium nitrite were provided by Sigma-Aldrich (St. Louis, MO, USA). Ethanol and sodium hydroxide were obtained from Echo Chemical Co. (Miaoli, Taiwan) and Choneye Chemical Co. (Taipei, Taiwan), respectively. Sodium phosphate monobasic was purchased from Shimakyu's Pure Chemical Co. (Osaka, Japan).

\section{Preparation of extract \\ Material}

CF was sourced from the Hearty Farm, Yunlin, Taiwan. The CF seeds were dried whole in a hot air circulating oven at $30{ }^{\circ} \mathrm{C}$ for 72 hours for water removal and mold prevention. The processed CF seeds were stored in a freezer at $-30{ }^{\circ} \mathrm{C}$ prior to experiments.

\section{Water extraction}

Deionized (DI) water was the solvent used for extraction. $1 \mathrm{~g} \mathrm{CF}$ seeds and $100 \mathrm{~g}$ DI water were combined, stirred at $25^{\circ} \mathrm{C}$ for 1 hour, and then filtered to obtain the water extract (WE) of CF.

\section{Ethanol extraction}

CF extraction was performed using $32.5 \mathrm{wt} \%$ ethanol as the solvent. The proportion of ethanol extract used was based on the ethanol ratio used in the two-phase system. The weights of CF seeds and ethanol aqueous solution were $1 \mathrm{~g}$ and $100 \mathrm{~g}$, respectively. The solution was stirred at $25{ }^{\circ} \mathrm{C}$ for 1 hour and subsequently filtered to obtain a $32.5 \mathrm{wt} \%$ ethanol extract (AE) of CF.

\section{Two-phase system extraction}

The two-phase solution was prepared from $32.5 \mathrm{~g}$ of ethanol, $52.5 \mathrm{~g}$ of DI water, and $15 \mathrm{~g}$ of ammonium sulfate. $1 \mathrm{~g}$ $\mathrm{CF}$ seeds and $100 \mathrm{~g}$ two-phase system were mixed. After the two-phase $\mathrm{CF}$ extract was stirred at $25^{\circ} \mathrm{C}$ for 1 hour and then filtering, the filtered two-phase $\mathrm{CF}$ extract was 
poured into a separating funnel to separate the top phase from the bottom phase. After standing for $5 \mathrm{~min}$, the top of the two-phase system extract (TTE) and the bottom of the two-phase system extract (BTE) were obtained.

\section{Separated single-phase extraction of two-phase system}

The above-mentioned two-phase system solution was prepared. After the top and bottom phases were separated, CF was extracted from each phase. The weights of CF seeds and the top phase or the bottom phase was set $1 \mathrm{~g}$ and 100 $\mathrm{g}$, respectively, and the solution was stirred for $1 \mathrm{~h}$ at $25^{\circ} \mathrm{C}$ then filtered. The separated top of the two-phase system extract (STTE) and the separated bottom of the two-phase system extract (SBTE) were obtained for comparison with the two-phase system extraction, TTE, and BTE. Figure 1 mixture was continuously stirred for 5 minutes. Subsequently, $1.5 \mathrm{~mL}$ of $1 \mathrm{M} \mathrm{NaOH}$ was added to the mixture to react for 60 minutes. The spectrophotometer was used to detect its absorbance at a wavelength of $510 \mathrm{~nm}$. This method used quercetin as the standard, and the total flavonoid content was expressed as milligrams of quercetin equivalent $(\mathrm{QE})$ per gram of $\mathrm{CF}$ dry extract.

\section{DPPH radical scavenging ability}

This experiment referred to the test method of Tsai [30] and Chang [31] in which $2 \mathrm{~mL}$ of $0.2 \mathrm{mM}$ DPPH prepared with $95 \%$ ethanol solution was added to $2 \mathrm{~mL}$ of CF extract and mixed evenly. After 30 minutes of reacting in darkness, the absorbance of the solution was measured at $517 \mathrm{~nm}$, and DPPH radical scavenging activity was calculated using the following equation:

$$
\text { DPPH radical scavenging ability }(\%)=\left(1-\frac{\text { Abs.sample }}{\text { Abs.blank }}\right) \times 100 \% \text {. }
$$

shows the six CF extracts by different experimental procedures in this study.

\section{Total phenolic content}

According to the test method of Huang [26] and Huang [27], $0.3 \mathrm{~mL}$ of $\mathrm{CF}$ extract was added to $1.5 \mathrm{~mL}$ of $1 \mathrm{~N}$ Folin-Ciocalteu reagent and $1.2 \mathrm{~mL}$ of $15 \% \mathrm{Na}_{2} \mathrm{CO}_{3}$ for reaction in darkness for 30 minutes, and a spectrophotometer at a wavelength of $765 \mathrm{~nm}$ was used to detect its absorbance value. The experimental standard chemical used was gallic acid, and the total phenolic content was expressed as milligrams of gallic acid equivalent (GAE) per gram of CF dry extract.

\section{Total flavonoid content}

This experiment referred to the research method of Chan [28] and Lin [29]. In brief, $1 \mathrm{~mL}$ of CF extract was added to $0.15 \mathrm{~mL}$ of $5 \% \mathrm{NaNO}_{2}$ and mixed until homogeneous. After 5 minutes, $0.3 \mathrm{~mL}$ of $10 \% \mathrm{AlCl}_{3}$ was added, and the

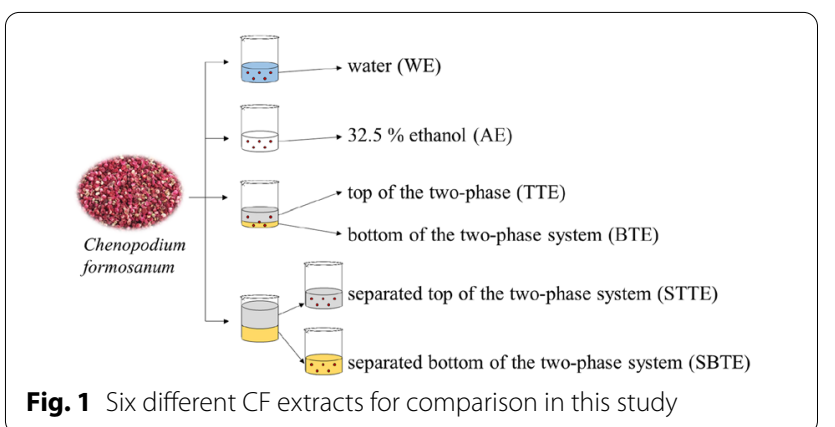

The $\mathrm{IC}_{50}$ of the DPPH radical scavenging activity was calculated from the curve of DPPH radical scavenging ability versus concentration. $\mathrm{IC}_{50}$ indicates how many samples are needed for the DPPH radical scavenging ability to reach $50 \%$. The lower the $\mathrm{IC}_{50}$, the more effective the antioxidant capacity of the sample is.

\section{ABTS radical scavenging activity}

With reference to a previously described method [27, 32], an equal volume of $7 \mathrm{mM}$ ABTS aqueous solution and $2.45 \mathrm{mM}$ potassium persulfate solution was mixed uniformly and placed in an environment at $4{ }^{\circ} \mathrm{C}$ in darkness for 16 hours. The background absorbance was diluted to $0.7 \pm 0.02$ by using $95 \%$ ethanol. Subsequently, $0.4 \mathrm{~mL}$ of CF extract and $3.6 \mathrm{~mL}$ of ABTS solution were mixed evenly in darkness for 10 minutes. The absorbance was measured at $734 \mathrm{~nm}$, and the ABTS radical scavenging activity was calculated using the following equation:

$$
\begin{aligned}
& \text { ABTS radical scavenging ability (\%) } \\
& =\left(1-\frac{\text { Abs.sample }}{\text { Abs.blank }}\right) \times 100 \%
\end{aligned}
$$

The method for attaining the $\mathrm{IC}_{50}$ of the ABTS radical scavenging activity was the same as that of the DPPH radical scavenging ability.

\section{Ferric reducing power}

With reference to a previously reported method [29, 33], $1 \mathrm{~mL}$ of CF extract, $0.5 \mathrm{~mL}$ of $0.2 \mathrm{M}$ phosphate buffer solution (pH 6.6) and $0.5 \mathrm{~mL}$ of $1 \% \mathrm{~K}_{3} \mathrm{Fe}(\mathrm{CN})_{6}$ solution 


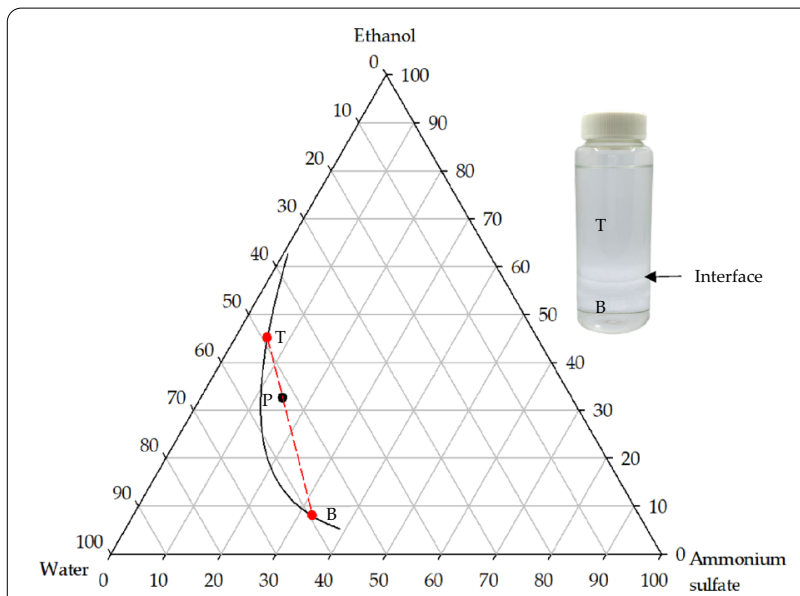

Fig. 2 Phase diagram of ethanol, ammonium sulfate, and water. P: experimental component condition; $\mathrm{T}$ and $\mathrm{B}$ are the top and bottom phases of the two-phase system, respectively

were mixed at $50{ }^{\circ} \mathrm{C}$ for 20 minutes in a water bath then rapidly cooled. Subsequently, $0.5 \mathrm{~mL}$ of $0.1 \% \mathrm{CCl}_{3} \mathrm{COOH}$ solution, $2.5 \mathrm{~mL}$ of DI water, and $0.5 \mathrm{~mL}$ of $0.1 \% \mathrm{FeCl}_{3}$ solution were added to the mixture. After 10 minutes of standing in darkness, the mixture was analyzed using the spectrophotometer at a wavelength of $700 \mathrm{~nm}$. Vitamin $C$ was used as the standard for determining the ferric reducing power. The ferric reducing power was expressed as the milligrams of vitamin $\mathrm{C}$ equivalent (VCE) per gram of CF dry extract.

\section{Results and discussion Phase diagram}

Figure 2 shows the phase diagram of ethanol, ammonium sulfate, and water at $25{ }^{\circ} \mathrm{C}$. The black curve in the figure is the theoretical equilibrium phase diagram of the three components as described in the literature [34, 35]. The black dot $(\mathrm{P})$ in the phase diagram represents the experimental conditions of this study. The two red dots represent the top phase (T) and the bottom phase (B) of the two-phase system. The interface in the vial between the

Table 1 Extraction yield (\%) of CF in different extraction methods

\begin{tabular}{lc}
\hline Extract & Yield (\%) \\
\hline AE & $7.96 \pm 1.6$ \\
WE & $12.38 \pm 1.11$ \\
TTE & $3.55 \pm 0.96$ \\
BTE & $5.73 \pm 0.53$ \\
STTE & $3.70 \pm 0.68$ \\
SBTE & $8.59 \pm 0.47$ \\
\hline
\end{tabular}

top phase $(\mathrm{pH}=5.3)$ and the bottom phase $(\mathrm{pH}=5.9)$ is clearly demarcated. The volume ratio of the top and bottom phases in the vial corresponds to the segment ratio of $\mathrm{T}$ to $\mathrm{P}$ and $\mathrm{P}$ to $\mathrm{B}$ in the phase diagram called the tieline lever rule. The acidic $\mathrm{pH}$ values of the top phase and the bottom phase are beneficial for the extraction of $\mathrm{CF}$ [1].

\section{Extraction yield}

The extraction yield of CF depended on the extraction solution. Table 1 presents the extraction yields by dry weight of different extracts. The extraction yield of WE $(12.38 \% \pm 1.11 \%)$ was the highest of the different extraction solutions. The combined yields $(9.28 \%)$ of TTE (3.55\%) and BTE (5.73\%) comprise the overall yield in the two-phase system, and this value was between that of $\mathrm{AE}$ $(7.96 \% \pm 1.6 \%)$ and WE $(12.38 \% \pm 1.11 \%)$. The yield of TTE was lower than that of BTE, and that of STTE was lower than SBTE. A possible reason of this result may be that CF has more hydrophilic than hydrophobic components. This finding is consistent with the result of polysaccharides in extract from Gentiana scabra Bunge [36].

\section{Total phenol content}

Phenolic compounds are often used as indicators of antioxidant capacity because they have a strong ability to scavenge free radicals. Figure 3 shows the amount of GAE per gram of dry weight of CF extract. STTE had the highest total phenol content $(120.35 \pm 5.80 \mathrm{mg}$ of GAE/g of dry extract), followed by TTE (91.47 $\pm 8.23 \mathrm{mg} \mathrm{GAE} / \mathrm{g}$ dry extract), and BTE with the lowest total phenol content $(33.22 \pm 1.71 \mathrm{mg}$ GAE/g dry extract). The total phenol contents of AE and WE were 50.74 \pm 2.43 and 57.37 $\pm 6.41 \mathrm{mg}$ of GAE/g of dry extract. TTE and STTE had higher total phenol content than BTE and SBTE, respectively. A possible reason is that phenol migrated to the top phase in acidic conditions [37]. This result indicates

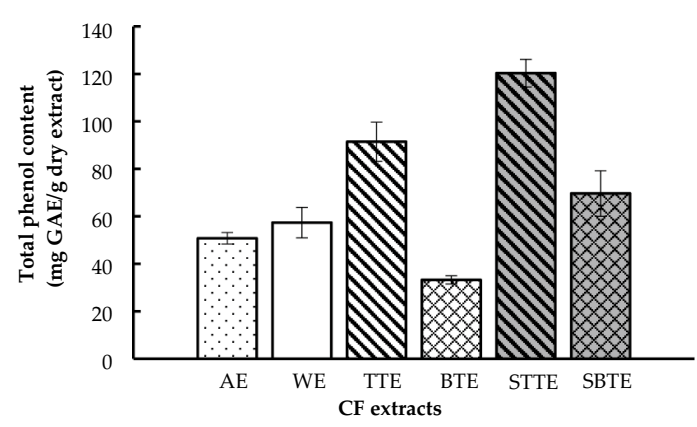

Fig. 3 Total phenol content of different CF extracts 


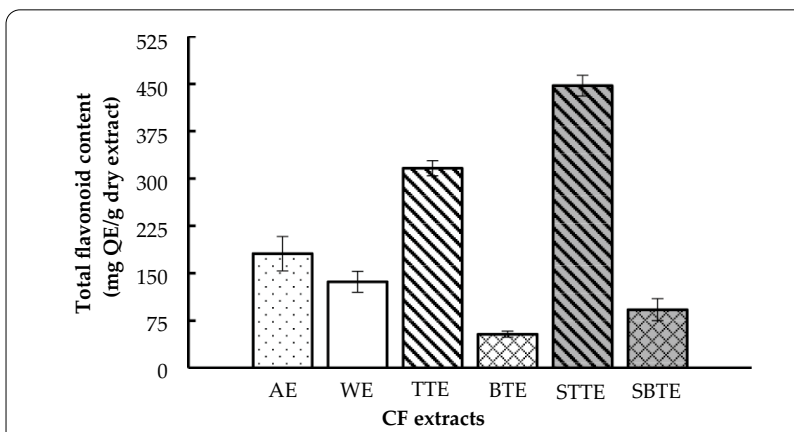

Fig. 4 Total flavonoid content of different CF extracts

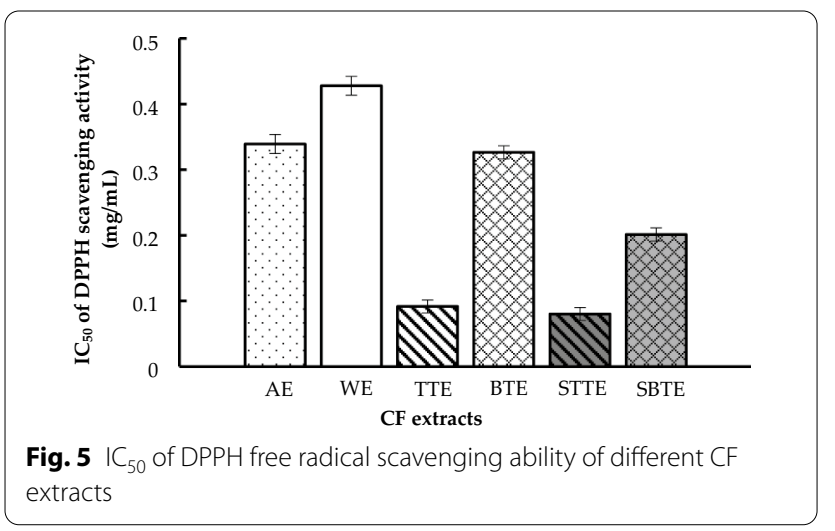

the consistency of CF extraction by using a two-phase system (TTE and BTE) and a separated single-phase system (STTE and SBTE).

\section{Total flavonoid content}

Flavonoids are often used as indicators of antioxidant capacity. If a sample has flavonoids, it will react with the developer to form an orange-red aluminum chelate. Fig. 4 shows the result of QE per gram of dry CF extract by using different extraction methods. STTE had the highest total flavonoid content $(447.06 \pm 16.57 \mathrm{mg} \mathrm{QE} / \mathrm{g}$ dry extract), followed by TTE (316.22 $\pm 11.89 \mathrm{mg} \mathrm{QE} / \mathrm{g}$ dry extract) and BTE with the lowest content (53.39 \pm $4.89 \mathrm{mg} \mathrm{QE} / \mathrm{g}$ dry extract). The total flavonoid contents of $\mathrm{AE}, \mathrm{WE}, \mathrm{BTE}$, and SBTE were much lower than that of STTE. Moreover, the two-phase extract and the separated single-phase system registered a similar result; the top phase had a higher flavonoid content than the bottom phase. This result was the same as Crotalaria sessiliflora L extracted using an ATPS [38].

\section{DPPH radical scavenging ability}

The DPPH radical is a stable free radical at a wavelength of $517 \mathrm{~nm}$. When the DPPH radical accepts electrons,
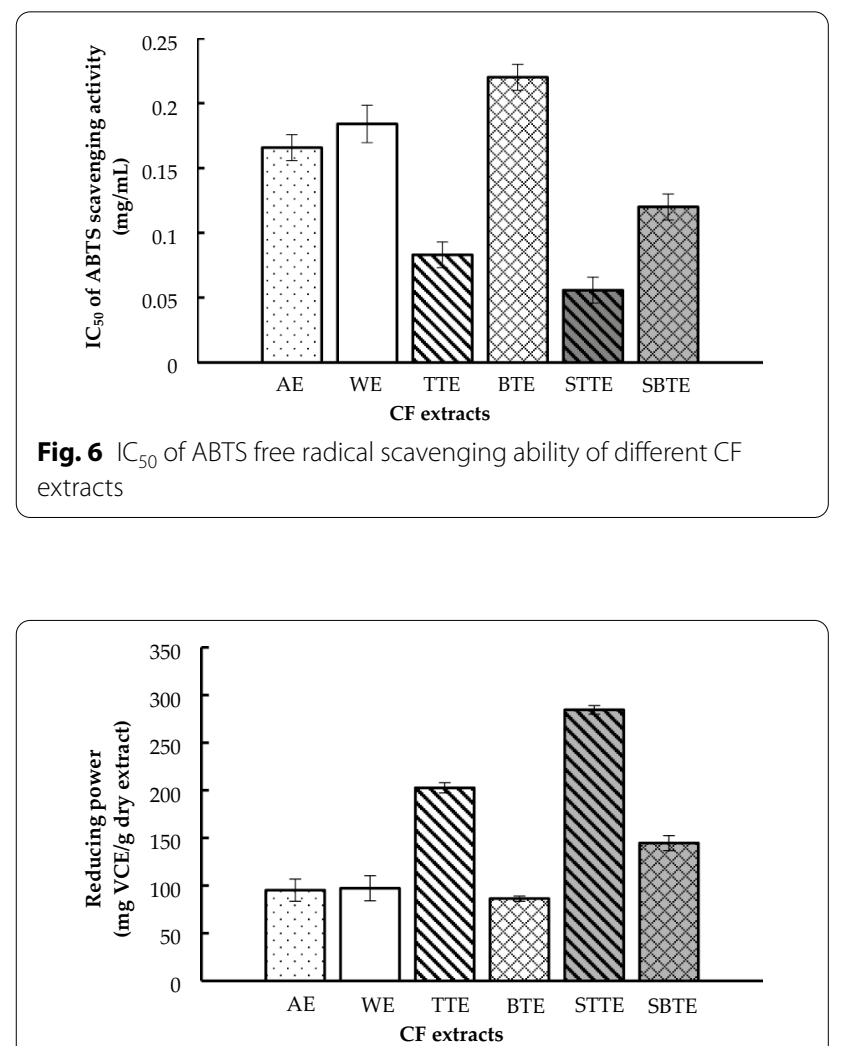

Fig. 7 Ferric reducing power of different CF extracts

the color changes from dark purple to light yellow. Fig. 5 illustrates that the lowest $\mathrm{IC}_{50}$ of the different extraction methods were achieved for STTE $(0.08 \pm 0.01 \mathrm{mg} / \mathrm{mL})$ and TTE $(0.09 \pm 0.01 \mathrm{mg} / \mathrm{mL})$, followed by SBTE $(0.20$ $\pm 0.01 \mathrm{mg} / \mathrm{mL})$. The $\mathrm{IC}_{50}$ values of $\mathrm{AE}, \mathrm{WE}, \mathrm{BTE}$ were far higher than those of STTE and TTE, between $0.33 \pm$ 0.01 and $0.43 \pm 0.01 \mathrm{mg} / \mathrm{mL}$. The result evinced a similar trend; the top phase had higher DPPH radical scavenging activity than the bottom phase did for the two-phase system (TTE and BTE) and the separated single-phase system (STTE and SBTE). The experimental data were compared with the literature [39], and the $\mathrm{IC}_{50}$ of $\mathrm{AE}$ and WE are nearly equal to the $\mathrm{IC}_{50}$ of water extract and organic solvent extract of CF, corroborating the results in this experiment.

\section{ABTS radical scavenging activity}

When an ABTS cation radical, which is stable at a wavelength of $734 \mathrm{~nm}$, is scavenged by a sample, the ABTS solution color changes from blue-green to colorless. The lighter the color of the ABTS solution, the higher the ABTS free radical scavenging ability of the sample is. The $\mathrm{IC}_{50}$ results in Fig. 6 indicate that STTE $(0.06 \pm 0.01 \mathrm{mg} /$ $\mathrm{mL})$ and TTE $(0.08 \pm 0.01 \mathrm{mg} / \mathrm{mL})$ displayed a superior antioxidant capacity because of their low $\mathrm{IC}_{50}$ values. The 
$\mathrm{IC}_{50}$ values of $\mathrm{AE}, \mathrm{WE}$, and $\mathrm{BTE}$ were between 0.17 and $0.22 \mathrm{mg} / \mathrm{mL}$, considerably higher than those of STTE and TTE. This result demonstrates that the top phases (TTE and STTE) have a higher ABTS free radical scavenging ability than do the bottom phases (BTE and SBTE), and this outcome is consistent with a previous report [23].

\section{Ferric reducing power}

If a sample manifests ferric reducing power, the oxidizing substance can stimulate electrons to terminate the oxidation reaction. Considering the amount of Prussian blue produced as an indicator, the more Prussian blue that is produced, the higher the antioxidant capacity is. Fig. 7 shows that STTE had the strongest reducing ability (284.48 $\pm 4.60 \mathrm{mg} \mathrm{VCE} / \mathrm{g}$ dry extract), followed by TTE (202.61 $\pm 5.34 \mathrm{mg}$ of VCE/g of dry extract). Furthermore, the two-phase extracts (TTE and BTE) and the separated single-phase system (STTE and SBTE) registered a similar result; the top phase had higher ferric reducing power than did the bottom phase.

Overall, TTE and STTE had the best antioxidant outcomes. However, TTE and STTE also showed the lower $\mathrm{CF}$ extraction yield. This consequence may result from $\mathrm{pH}$ of CF extracts. Ammonium sulfate has weak acidity in aqueous solutions, and this is extremely appropriate to separate bioproducts stable [34]. The $\mathrm{pH}$ values of the top phase and bottom phase are 5.3 and 5.9, respectively. Betanin, an effective antioxidant component in CF, has the strongest antioxidant capacity and stability with a $\mathrm{pH}$ of 5 [1]. Besides, phenolic compounds migrated to the top phase in acidic conditions [37]. The total phenol content and flavonoid content related to antioxidant capacity of TTE and STTE were higher than BTE and SBTE.

There are numerous papers on antioxidant activity of $\mathrm{CF}$ that have come out in recent years [40-47]. However, conventional methods to extract CF may be not efficient. ATPS has advantages of effective and economically viable separation for plant extraction [8,9]. Purifying of target compounds [22, 24], bioactive ingredients and antioxidant activity $[24,25]$ can be enhanced in ATPS compared with conventional methods. Therefore, APTS can provide a potential approach for large-scale production of bioactive compounds from $\mathrm{CF}$ in the future.

\section{Conclusions}

CF is endemic to Taiwan and considered a plant high in functional components. This study used a two-phase extraction system for $\mathrm{CF}$ and compared it with traditional solvent extraction. The results indicated that a two-phase extraction system has greater antioxidant capacity than traditional solvent extraction. CF extracted with the top phase of a two-phase system had superior antioxidant capacity in terms of total phenolic content, total flavonoid content, DPPH radical scavenging ability, ABTS radical scavenging ability, and ferric reducing power. The result confirms that the ethanol-ammonium sulfate-water two-phase system for extraction from CF can not only provide more appropriate extraction conditions, but can also deliver excellent performance in the antioxidant capacity of an extraction.

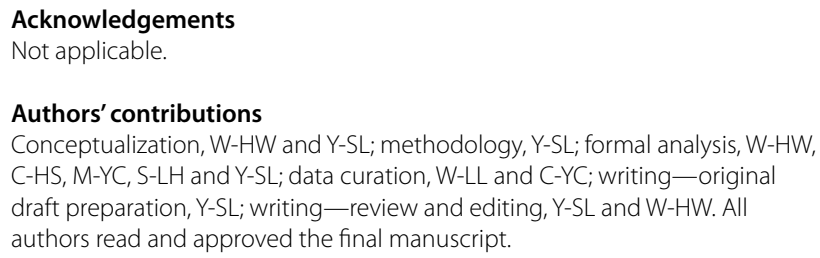

\section{Authors' contributions}

Conceptualization, W-HW and Y-SL; methodology, Y-SL; formal analysis, W-HW, C-HS, M-YC, S-LH and Y-SL; data curation, W-LL and C-YC; writing-original draft preparation, Y-SL; writing - review and editing, Y-SL and W-HW. All authors read and approved the final manuscript.

\section{Funding}

This research was funded by the Ministry of Science and Technology of Taiwan with grand program code MOST 110-2622-E-239-003.

\section{Availability of data and materials}

Not applicable.

\section{Declarations}

Ethics approval and consent to participate Not applicable.

\section{Consent for publication}

All authors have read and agreed to the version of the manuscript.

\section{Competing interests}

The authors declare that they have no competing interests.

\section{Author details}

${ }^{1}$ Department of Orthopedic Surgery, Changhua Christian Hospital, Changhua 500209, Taiwan. ${ }^{2}$ School of Medicine, Kaohsiung Medical University, Kaohsiung 807378, Taiwan. ${ }^{3}$ Department of Golden-Ager Industry Management, Chaoyang University of Technology, Taichung 413310, Taiwan. ${ }^{4}$ Department of Medical Imaging and Radiology, Shu-Zen Junior College of Medicine and Management, Kaohsiung 821004, Taiwan. ${ }^{5}$ College of Medicine, National Chung Hsing University, Taichung 402202, Taiwan. ${ }^{6}$ Department of Chemical Engineering, National United University, Miaoli 360001, Taiwan. ${ }^{7}$ Program in Materials and Chemical Engineering, National United University, Miaoli 360001, Taiwan. ${ }^{8}$ Miaoli District Agricultural Research and Extension Station, Council of Agriculture, Miaoli 363201, Taiwan. ${ }^{9}$ Institute of Food Safety and Health Risk Assessment, National Yang Ming Chiao Tung University, Taipei 112304, Taiwan.

Received: 21 October 2021 Accepted: 30 December 2021 Published online: 15 January 2022

References

1. Tsai PJ, Sheu CH, Wu PH, Sun YF. Thermal and pH stability of betacyanin pigment of djulis (Chenopodium formosanum) in Taiwan and their relation to antioxidant activity. J Agric Food Chem. 2010;58:1020-5.

2. Tsai PJ, Chen YS, Sheu CH, Chen CY. Effect of nanogrinding on the pigment and bioactivity of djulis (Chenopodium formosanum Koidz.). J Agric Food Chem. 2011;59:1814-20.

3. Castro-Enríquez DD, Montaño-Leyva B, Del Toro-Sánchez $C L$, JuarézOnofre JE, Carvajal-Millan E, Burruel-Ibarra SE, Tapia-Hernández JA, 
Barreras-Urbina CG, Rodríguez-Félix F. Stabilization of betalains by encapsulation-a review. J Food Sci Technol. 2020;57:1587-600.

4. Hsu BY, Lin SW, Inbaraj BS, Chen BH. Simultaneous determination of phenolic acids and flavonoids in Chenopodium formosanum Koidz. (djulis) by HPLC-DAD-ESI-MS/MS. J Pharm Biomed Anal. 2017;132:109-16.

5. Lee CW, Chen HJ, Xie GR, Shih CK. Djulis (Chenopodium formosanum) prevents colon carcinogenesis via regulating antioxidative and apoptotic pathways in rats. Nutrients. 2019;11:2168.

6. Hong YH, Huang YL, Liu YC, Tsai PJ. Djulis (Chenopodium formosanum Koidz.) water extract and its bioactive components ameliorate dermal damage in UVB-irradiated skin models. BioMed Res Int. 2016;2016:7368797.

7. Chen SY, Chu CC, Chyau CC, Yang JW, Duh PD. Djulis (Chenopodium formosanum) and its bioactive compounds affect vasodilation, angiotensin converting enzyme activity, and hypertension. Food Biosci. 2019:32:100469.

8. Bi PY, Dong HR, Yuan YC. Application of aqueous two-phase flotation in the separation and concentration of puerarin from Puerariae extract. Sep Purif Technol. 2010;75:402-6.

9. Iqbal M, Tao Y, Xie S, Zhu Y, Chen D, Wang X, Huang L, Peng D, Sattar A, Shabbir MAB, Hussain HI. Aqueous two-phase system (ATPS): an overview and advances in its applications. Bio Proced Online. 2016;18:18.

10. Guo YX, Han J, Zhang DY, Wang LH, Zhou LL. An ammonium sulfate/ethanol aqueous two-phase system combined with ultrasonication for the separation and purification of lithospermic acid B from Salvia miltiorrhiza Bunge. Ultrason Sonochem. 2012;19:719-24.

11. Tan Z, Li F, Xu X. Isolation and purification of aloe anthraquinones based on an ionic liquid/salt aqueous two-phase system. Sep Purif Technol. 2012:98:150-7.

12. Wang T, Xu WJ, Wang SX, Kou P, Wang P, Wang XQ, Fu YJ. Integrated and sustainable separation of chlorogenic acid from blueberry leaves by deep eutectic solvents coupled with aqueous two-phase system. Food Bioprod Process. 2017:105:205-14.

13. Xavier L, Freire S, Vidal-Tato I, Gonzalez-Alvarez J. Aqueous two-phase systems for the extraction of phenolic compounds from eucalyptus (Eucalyptus globulus) wood industrial wastes. J Chem Technol Biotechnol. 2014;89:1772-8.

14. Jiang $X M$, Lu YM, Tan CP, Liang Y, Cui B. Combination of aqueous twophase extraction and cation-exchange chromatography: new strategies for separation and purification of alliin from garlic powder. J Chromatogr B. 2014;957:60-7.

15. Dang YY, Zhang H, Xiu ZL. Microwave-assisted aqueous two-phase extraction of phenolics from grape (Vitis vinifera) seed. J Chem Technol Biotechnol. 2014;89:1576-81.

16. He A, Dong B, Feng $X$, Yao S. Extraction of bioactive ginseng saponins using aqueous two-phase systems of ionic liquids and salts. Sep Purif Technol. 2017:196:270-80.

17. Liu Y, Han J, Wang Y, Lu Y, Zhang G, Sheng C, Yan Y. Selective separation of flavones and sugars from honeysuckle by alcohol/salt aqueous twophase system and optimization of extraction process. Sep Purif Technol. 2013:118:776-83.

18. Zhang X, Teng G, Zhang J. Ethanol/salt aqueous two-phase system based ultrasonically assisted extraction of polysaccharides from Lilium davidivar unicolor Salisb: physicochemical characterization and antiglycation properties. J Mol Liq. 2018;256:497-506.

19. Lin Y, Zeng H, Wang K, Lin H, Li P, Huang Y, Zhou S, Zhang W, Chen C, Fan H. Microwave-assisted aqueous two-phase extraction of diverse polysaccharides from Lentinus edodes: process optimization, structure characterization and antioxidant activity. Int J Biol Macromol. 2019;136:305-15.

20. Tan Z, Wang C, Yi Y, Wang H, Li M, Zhou W, Tan S, Li F. Extraction and purification of chlorogenic acid from ramie (Boehmeria nivea L. Gaud) leaf using an ethanol/salt aqueous two-phase system. Sep Purif Technol. 2014;132:396-400.

21. Zhou S, Wu X, Huang Y, Xie X, Lin Y, Fan H, Luo L, Zhang W, Tang JZ. Microwave-assisted aqueous two-phase extraction of alkaloids from Radix Sophorae Tonkinensis with an ethanol/ $\mathrm{Na}_{2} \mathrm{HPO}_{4}$ system: process optimization, composition identification and quantification analysis. Ind Crop Prod. 2018;122:316-28.

22. Cheng Z, Cheng L, Song H, Yu L, Zhong F, Shen Q, Hu H. Aqueous two-phase system for preliminary purification of lignans from fruits of Schisandra chinensis Baill. Sep Purif Technol. 2016;166:16-25.
23. Dordevic T, Antov M. Ultrasound assisted extraction in aqueous twophase system for the integrated extraction and separation of antioxidants from wheat chaff. Sep Purif Technol. 2017:182:52-8.

24. Li F, Li Q, Wu S, Tan Z. Salting-out extraction of allicin from garlic (Allium sativum L.) based on ethanol/ammonium sulfate in laboratory and pilot scale. Food Chem. 2017;217:91-7.

25. Fu XQ, Zhang GL, Deng L, Dang YY. Simultaneous extraction and enrichment of polyphenol and lutein from marigold (Tagetes erecta L.) flower by an enzyme-assisted ethanol/ammonium sulfate system. Food Func. 2019;10:266-76.

26. Huang WY, Lin YR, Ho RF, Liu HY, Lin YS. Effects of water solutions on extracting green tea leaves. Sci World J. 2013;2013:368350.

27. Huang SL, Wang WH, Zhong XY, Lin CT, Lin WS, Chang MY, Lin YS. Antioxidant properties of Jatropha curcas L. seed shell and kernel extracts. Appl Sci. 2020;10:3279

28. Chan CF, Wu CT, Huang WY, Lin WS, Wu HW, Huang TK, Chang MY, Lin YS. Antioxidation and melanogenesis inhibition of various Dendrobium tosaense extracts. Molecules. 2018;23:1810.

29. Lin YS, Lin WS, Tung JW, Cheng YC, Chang MY, Chen CY, Huang SL. Antioxidant capacities of jujube fruit seeds and peel pulp. Appl Sci. 2020;10:6007.

30. Tsai CC, Chan CF, Huang WY, Lin JS, Chan P, Liu HY, Lin YS. Applications of Lactobacillus rhamnosus spent culture supernatant in cosmetic antioxidation, whitening and moisture retention applications. Molecules. 2013;18:14161-71.

31. Chang MY, Lin YY, Chang YC, Huang WY, Lin WS, Chen CY, Huang SL, Lin YS. Effects of infusion and storage on antioxidant activity and total phenolic content of black tea. Appl Sci. 2020;10:2685.

32. Huang WY, Lee PC, Hsu JC, Lin YR, Chen HJ, Lin YS. Effects of water quality on dissolution of yerba mate extract powders. Sci World J. 2014:2014:768742.

33. Wu CT, Agrawal DC, Huang WY, Hsu HC, Yang SJ, Huang SL, Lin YS Functionality analysis of spent coffee ground extracts obtained by the hydrothermal method. J Chem. 2019;2019:4671438.

34. Wang $Y$, Yan $Y$, Hu S, Han J, Xu X. Phase diagrams of ammonium sulfate + ethanol/1-propanol/2-propanol + water aqueous two-phase systems at 298.15 K and correlation. J Chem Eng Data. 2010;55:876-81.

35. Fu H, Yang ST, Xiu Z. Phase separation in a salting-out extraction system of ethanol-ammonium sulfate. Sep PurifTechnol. 2015;148:32-7.

36. Cheng Z, Song H, Cao X, Shen Q, Han D, Zhong F, Hu H, Yang Y. Simultaneous extraction and purification of polysaccharides from Gentiana scabra Bunge by microwave-assisted ethanol-salt aqueous two-phase system. Ind Crops Prod. 2017;102:75-87.

37. Xavier L, Freire MS, Vidal-Tato I, González-Álvarez J. Recovery of phenolic compounds from Eucalyptus wood wastes using ethanol-salt-based aqueous two-phase systems. Maderas, Cienc tecnol. 2017;19:3-14.

38. Xie X, Zhu D, Zhang W, Huai W, Wang K, Huang X, Zhou L, Fan H. Microwave-assisted aqueous two-phase extraction coupled with high performance liquid chromatography for simultaneous extraction and determination of four flavonoids in Crotalaria sessiliflora L. Ind Crop Prod. 2017:95:632-42.

39. Li PH, Chan YJ, Lu WC, Huang DW, Chang TC, Chang WH, Nie XB, Jiang CX, Zhang XL. Bioresource utilization of djulis (Chenopodium formosanum) biomass as natural antioxidants. Sustainability. 2020;12:5926.

40. Chuang KJ, Chen ZJ, Cheng CL, Hong GB. Investigation of the antioxidant capacity, insecticidal ability and oxidation stability of Chenopodium formosanum seed extract. Int J Mol Sci. 2018;19(9):2726.

41. Chen MN, Chan CF, Huang SL, Lin YS. Green biosynthesis of gold nanoparticles using Chenopodium formosanum shell extract and analysis of the particles' antibacterial properties. J Sci Food Agric. 2019;99(7):3693-702.

42. Lin YH, Lin YK, Chan ST, Chun YM, Lin YT, Kan KW, Yu CH. Anti cutaneous aging effect of red djulis (Chenopodium formosanum) extract on gene expression of human dermal fibroblast. Preprints 2019:2019090028.

43. Kuo HC, Kwong HK, Chen HY, Hsu HY, Yu SH, Hsieh CW, Lin HW, Chu YL, Cheng KC. Enhanced antioxidant activity of Chenopodium formosanum Koidz. by lactic acid bacteria: Optimization of fermentation conditions. PLoS ONE. 2021;16(5):e0249250.

44. Lin YK, Chung YM, Lin YH, Lin YH, Hu WC, Chiang CF. Health functional properties of unhulled red djulis (Chenopodium formosanum) in antiaging. Int J Food Prop. 2021;24(1):833-44. 
45. Lu BJ, Lin TC, Chao HR, Tsai CH, Lu JH, Tsai MH, Chang CT, Hsieh H, Lu IC, Arcega RD, Chang WH, Chen HL, Mansor WNW, Lee YC. The impact of air or nitrogen non-thermal plasma on variations of natural bioactive compounds in Djulis (Chenopodium formosanum Koidz.) seed and the potential effects for human health. Atmosphere. 2021;12(11):1375.

46. Tsai TY, Lin RJ, Liu C, Tseng YP, Chan LP, Liang CH. Djulis supplementation against oxidative stress and ultraviolet radiation-induced cell damage: the influence of antioxidant status and aging of skin in healthy subjects. J Cosmet Dermatol. 2021. https://doi.org/10.1111/jocd.14482.

47. Wu CT, Wang WH, Lin WS, Hu SY, Chen CY, Chang MY, Lin YS, Li CP.

Effects of different Chenopodium formosanum parts on antioxidant capacity and optimal extraction analysis by Taguchi method. Materials. 2021;14(16):4679

\section{Publisher's Note}

Springer Nature remains neutral with regard to jurisdictional claims in published maps and institutional affiliations.

\section{Submit your manuscript to a SpringerOpen ${ }^{\circ}$ journal and benefit from:}

- Convenient online submission

- Rigorous peer review

- Open access: articles freely available online

- High visibility within the field

- Retaining the copyright to your article

Submit your next manuscript at $\boldsymbol{\nabla}$ springeropen.com 